\title{
Chemokine involvement in tetracycline-induced pleuritis
}

\author{
E.J. Miller*, O. Kajikawa**, S. Pueblitz ${ }^{+}$, R.W. Light ${ }^{++}$, K.K. Koenig*, S. Idell*
}

Chemokine involvement in tetracycline-induced pleuritis. E.J. Miller, O. Kajikawa, S. Pueblitz, R.W. Light, K.K. Koenig, S. Idell. (C)ERS Journals Ltd 1999.

ABSTRACT: Sclerosants such as tetracycline (TCN) have often been used in the control of malignant pleural effusions. Although the resultant inflammatory response is probably important in the ensuing pleural fibrosis, the signals responsible for the cellular influx into the pleural space following TCN instillation are not well understood. This study, therefore, sought to determine whether the chemokines interleukin-8 (IL-8), growth-related protein (Gro), and monocyte chemotactic protein-1 (MCP-1) were locally elaborated within the first $72 \mathrm{~h}$ following intrapleural TCN administration.

TCN induced an exudative effusion with high lactate dehydrogenase activity. Although there was no significant change in the pleural fluid total leukocyte content, the median polymorphonuclear neutrophil concentration decreased from $1.067 \times 10^{6}$ to $2.03 \times 10^{5}$ cells $\cdot \mathrm{mL}^{-1}$ between 24 and $72 \mathrm{~h}$, whereas the median macrophage concentration increased from $1.44 \times 10^{5}$ to $5.98 \times 10^{5}$ cells $\mathrm{mL}^{-1}$ over the same period. Furthermore, IL-8, Gro and MCP-1 concentrations decreased between 24 and $72 \mathrm{~h}$. Immunocytochemistry indicated expression of IL-8 by pleural mesothelial cells $24 \mathrm{~h}$, but not $72 \mathrm{~h}$, following TCN administration.

The data suggest that local elaboration of interleukin-8 and growth-related protein, in part of mesothelial origin, may influence neutrophil recruitment in tetracyclineinduced pleuritis.

Eur Respir J 1999; 14: 1387-1393.
Each year, in the USA, 1.5 million individuals develop a pleural effusion [1]. Malignant pleural effusions can occur as a result of tumour growth, and are often associated with various neoplasms, including carcinomas of the lung, breast or intestinal tract. Treatment of patients with malignant effusions can involve pleural fluid aspiration for symptomatic relief. In some cases, more aggressive palliative measures are necessary to manage the pleural effusion.

Pleurodesis, the production of adhesions between the visceral and parietal pleura, is often effective in the relief of malignant pleural effusions. Chemical pleurodesis can be achieved by the injection of an irritant, such as tetracycline (TCN) or one of its derivatives doxycycline or minocycline, into the pleural space [2-4]. Intrapleural TCN administration produces intense inflammation with initial neutrophil influx, followed by an increase in pleural macrophage and lymphocyte numbers over the subsequent $48 \mathrm{~h}$. This is accompanied by mesothelial denudement, and the rapid deposition of pleural fibrin, which serves as a scaffolding for fibroblasts to span the pleural compartment. The ensuing fibrosis results in the fusion of the visceral and parietal pleura and the obliteration of the pleural space. While the anatomical and temporal features of the fibrotic response are well appreciated, the mechanisms involved in the inflammatory reaction to $\mathrm{TCN}$ are incompletely understood.

Interleukin-8 (IL-8), a neutrophil chemoattractant of the $\alpha$-chemokine family, has been implicated in lung inflam-
Depts of*Biochemistry, ${ }^{+}$Pathology \& ${ }^{\star} \mathrm{Me}-$ dical Specialities, The University of Texas Health Center at Tyler, Tyler, Texas **Dept of Veterans Affairs, Medical Center, Seattle, Washington ${ }^{++}$Dept of Medicine, Saint Thomas Hospital and Vanderbilt University, Nashville, Tennessee, USA

Correspondence: E.J. Miller, The University of Texas Health Center at Tyler, 11937 US Highway 271, Tyler Texas 75708-3154 USA. Fax: 90387770015954

\section{Keywords: Animal model}

chemokines

macrophage

neutrophil

pleurodesis

tetracycline

Received: June 31998

Accepted after revision June 211999

This work was supported in part by National HL 45018. E.J. Miller is a Parker B. Francis Fellow. Institutes of Health grants No. HL 55622 and

mation and injury [5] and pleuritis in both humans and rabbits. IL-8 can be secreted by numerous cell types including mesothelial cells, which cover the surfaces of the lung, mediastinum, thoracic wall and diaphragm. However, its role in TCN-induced pleuritis has not been fully elucidated. The purpose of this study was to determine whether $\alpha$ - and $\beta$-chemokines are involved in the TCNassociated inflammatory response, and to determine the temporal pattern of their expression. In particular, this study sought to determine whether IL-8 could contribute to the early influx of neutrophils in TCN-induced pleuritis in rabbits.

\section{Materials and methods}

\section{Study animals}

All animal work was approved by the Institutional Animal Care and Use Committees at the University of Texas Health Center and Vanderbilt University. Three groups (six animals per group) of female New Zealand White rabbits, 4-5 months old and weighing $2 \mathrm{~kg}$, were used.

\section{Study design}

Three groups of rabbits were used with each animal acting as its own control. In the first two groups, a baseline blood sample was drawn before TCN administration and 
compared to samples drawn prior to sacrificing the animal at either 24 or $72 \mathrm{~h}$ post-TCN administration. Since baseline pleural fluid samples could not be taken prior to TCN administration, the cellular and selected chemokine content of pleural fluid collected after 24 or $72 \mathrm{~h}$, immediately post mortem, were compared. The third group, which received talc as a sclerosant, were only examined for selected chemokine content of pleural fluid collected after 24 or $72 \mathrm{~h}$.

\section{Induction of pleuritis}

The animals were anaesthetized with ketamine $(250 \mathrm{mg})$ and xylazine $(30 \mathrm{mg})$ i.m. A small incision was then made over the lateral aspect of the 3rd or 4th left rib using a No. 10 scalpel. TCN (Sigma, St Louis, MO, USA) was freshly prepared as an injectable solution (TCN $20 \mathrm{mg} \cdot \mathrm{mL}^{-1}$; ascorbic acid $2.5 \mathrm{mg} \cdot \mathrm{mL}^{-1}$; lidocaine $1 \mathrm{mg} \cdot \mathrm{mL}^{-1}$ ), and filter sterilized. TCN solution $(3 \mathrm{~mL})$ was then injected into the pleural space using a $5.08-\mathrm{cm} 18-\mathrm{G}$ animal feeding needle. Animals were sacrificed at 24 and $72 \mathrm{~h}$ after intrapleural TCN administration by intravenous Nembutal $\left(35 \mathrm{mg} \cdot \mathrm{kg}^{-1}\right)$. A further group of animals received talc $\left(200 \mathrm{mg} \cdot \mathrm{kg}^{-1}\right)$ i.p. as previously described [6].

\section{Fluid sampling and tissue collection}

A baseline peripheral blood sample, from each animal, was collected (into $15 \%$ ethylenediaminetetraacetic acid) 1 $\mathrm{h}$ prior to treatment (Pre-Tx). Peripheral blood samples were then collected just prior to euthanasia at either 24 or $72 \mathrm{~h}$ after administration of TCN. The animals were then sacrificed and pleural fluid was collected in $0.9 \%$ sodium citrate post mortem. The pleural fluids were centrifuged at $500 \times g$ for $10 \mathrm{~min}$ and then stored at $-70^{\circ} \mathrm{C}$ until use. Pleural tissue was also removed by en bloc resection of the thorax and chest wall post mortem for histological examination and immunocytochemistry.

\section{Assays}

Total white cell counts, haemoglobin concentration and haematocrit were determined, for each blood sample, using a Coulter-S cell counter (Coulter Electronics, Inc., Hialeah, FL, USA). Pleural fluids were analysed for cellular content by the clinical laboratory at the University of Texas Health Center at Tyler, TX, USA. Total white blood cell (WBC) counts were determined using haemocytometry and differential cell counts were assessed using cytospin preparations stained using the Diff-Quick procedure (Baxter Scientific, McGaw Park, IL, USA). Total protein and lactate dehydrogenase (LDH) assays were performed as previously described [7]. In addition, the blood and pleural fluids were examined for IL-8, growth-related protein (Gro) and monocyte chemotactic protein-1 (MCP-1) using specific enzyme-linked immunosorbent assays (ELISAs) as previously described $[8,9]$.

The lungs and hemithoraces were removed en bloc and formalin fixed for immunohistochemistry. Samples of tissue were embedded in paraffin and $5 \mu \mathrm{m}$ thick sections prepared. The tissue sections were stained with haematoxylin and eosin for morphological assessments and with trichrome stain in order to detect collagen deposition.
Immunochemical analyses were performed as previously described [10]. Negative controls included substitution of isotypic control immunoglobulin $\mathrm{G}$ for the primary antibody. The tissue sections were stained for IL-8 using a polyclonal antiserum [11].

\section{Statistical analysis}

The data are expressed as mean \pm SD unless otherwise indicated. The differences between the groups were compared using one-way analysis of variance or the MannWhitney rank-sum test and an all pairwise multiple comparison procedure (Dunn's method or Tukey test) to test the statistical significance of the differences in median or mean values, respectively.

\section{Results}

Two groups of six New Zealand White rabbits were treated i.p. with TCN $\left(20 \mathrm{mg} \cdot \mathrm{mL}^{-1}, 3 \mathrm{~mL}\right)$ under sterile surgical conditions. One group was sacrificed after $24 \mathrm{~h}$, the other group after $72 \mathrm{~h}$. The early interval was chosen in order to evaluate the expression of IL- 8 and other selected chemokines during an initial acute inflammatory phase (24 h) during which pleural loculation and fibrosis had not yet occurred. In addition, the animals were studied at a later phase ( $72 \mathrm{~h}$ ) characterized by florid loculation, pleural fibrosis and collagen deposition within transpleural adhesions. The animals developed unilateral pleural effusions (up to $10 \mathrm{~mL}$ ) after $24 \mathrm{~h}$, and the effusion persisted for 72 h.

Intrapleural instillation of TCN caused a significant fall in the median haematocrit from the Pre-TX value after $24 \mathrm{~h}$ ( $<<0.05$, Dunn's method) (fig. 1a). However, after $72 \mathrm{~h}$, the median value had returned to its Pre-TX value. There was also a significant drop in the mean haemoglobin concentration from its Pre-TX value $24 \mathrm{~h}$ after TCN adminiistration ( $p<0.05$, Tukey test). However, the haemoglobin concentration after $72 \mathrm{~h}$ had also returned to its Pre-TX value. There were significant increases in the numbers of both total peripheral WBCs (fig. 2a) and total peripheral polymorphonuclear neutrophils (PMNs; fig. 2b) following intrapleural instillation of TCN. After $24 \mathrm{~h}$, the mean WBC concentration increased from the Pre-TX value $(\mathrm{p}<0.05$, Tukey test), but had returned to normal after 72 $h$. Furthermore, there was a significant increase in the mean peripheral blood PMN concentration from that during the first $24 \mathrm{~h}(\mathrm{p}<0.05$, Tukey test). As with WBCs, after $72 \mathrm{~h}$, the PMN concentration was not significantly different from the Pre-TX value.

Since the leukocytosis was initially neutrophilic and resolved into a more monocytic predominance after $72 \mathrm{~h}$, the plasma concentrations of IL- 8 , Gro and the $\beta$-chemokine MCP-1 were measured prior to, and 24 and $72 \mathrm{~h}$ after, TCN administration using specific ELISAs. No significant changes $(p>0.05)$ in the plasma chemokine concentrations were detected following intrapleural administration of TCN (fig. 3).

To characterize the local inflammatory response, the pleural fluid cellular and selected solute concentrations were examined. Cellular damage, as indicated by the high $\mathrm{LDH}$ activity, occurred within the first $24 \mathrm{~h}$ following TCN 

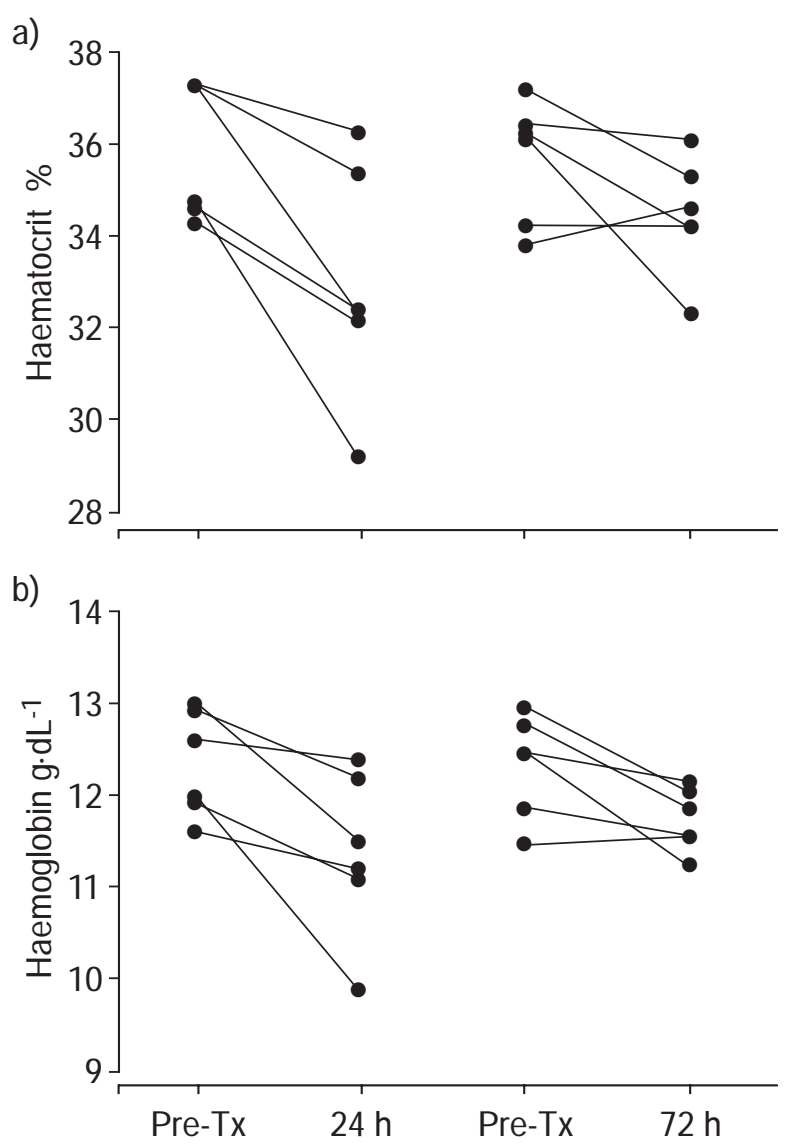

Fig. 1. - Blood haematocrit and haemoglobin concentration. a) Intrapleural instillation of tetracycline caused a significant drop in the median haematocrit from the pretreatment (pre-TX) value after $24 \mathrm{~h}(\mathrm{p}<0.05$, Dunn's method). The median value after $72 \mathrm{~h}$ was not significantly different from that pre-TX. b) There was also a significant drop in the mean haemoglobin concentration from the pre-TX value $(\mathrm{p}<0.05$, Tukey test). The haemoglobin concentration after $72 \mathrm{~h}$ was not significantly different from that pre-TX.

injection (fig. 4). However, the median LDH activity of the pleural fluid decreased significantly between 24 and $72 \mathrm{~h}$ following TCN administration $(\mathrm{p}=0.002$, MannWhitney). This was not the case with respect to the total protein concentration of the effusion, and there was no significant change in the total protein concentration over the same period ( $p=0.41$ ) (fig. 4). There was an initial leukocytosis, primarily neutrophilic in nature, which had lessened by $72 \mathrm{~h}$ (fig. 5). The Mann-Whitney rank-sum test indicated that the median concentration of PMNs in the pleural fluid $24 \mathrm{~h}$ after TCN administration was significantly higher $(p=0.009)$ than that after 72 h. However, there was no significant difference in the concentration of total WBCs in the pleural fluid after 24 or $72 \mathrm{~h}$ $(\mathrm{p}=0.485)$. Although there was a small increase in the mean pleural macrophage concentration between 24 and $72 \mathrm{~h}$ after TCN administration, the increase was not statistically significant (fig. 5).

Next the effusions were examined for specific chemokines. The effusions from a group of nine rabbits which had received talc as the sclerosing agent were also examined. In cases in which TCN had been used as the sclerosant, the concentrations of the $\alpha$-chemokines IL- 8
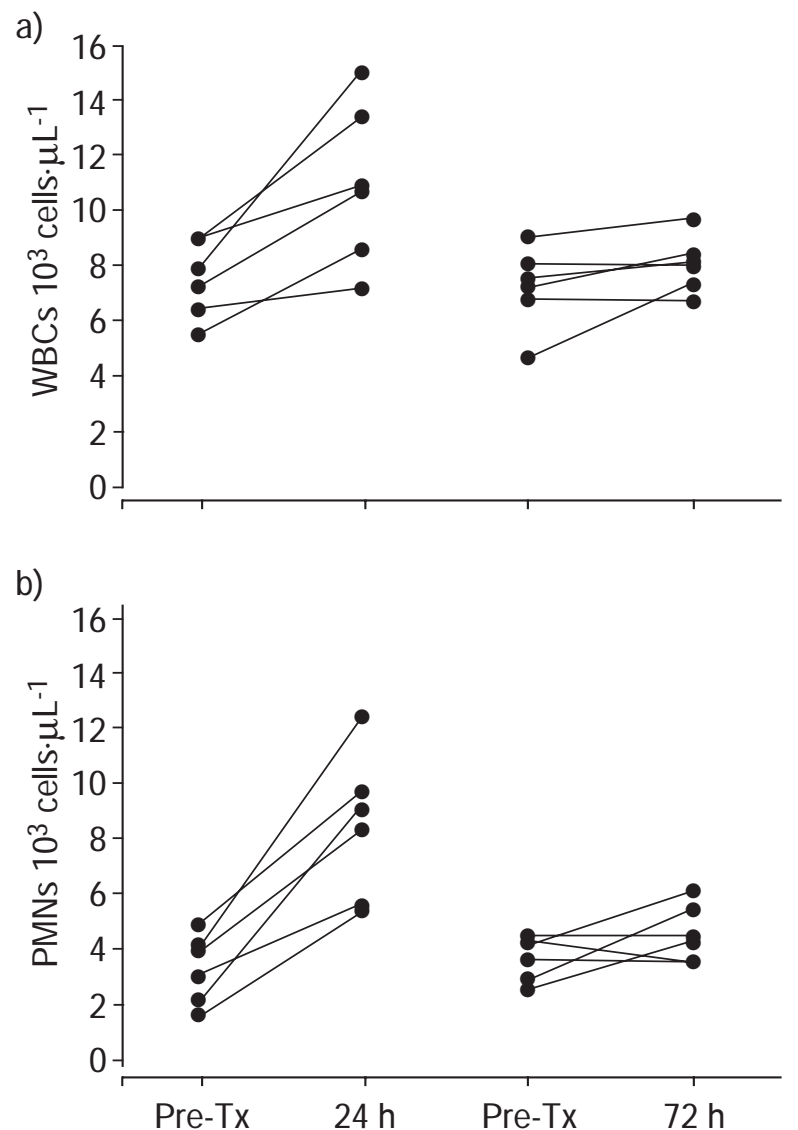

Fig. 2. - Peripheral blood total white blood cell (WBC) and polymorphonuclear neutrophil (PMN) concentration. a) Intrapleural instillation of tetracycline caused a significant drop in mean WBC from the pretreatment (pre-TX) value ( $<<0.05$, Tukey test). The value at $72 \mathrm{~h}$ was not significantly different from that pre-TX. b) There was a significant drop in the mean peripheral blood PMN concentration after $24 \mathrm{~h}(\mathrm{p}<0.05$, Tukey test). After $72 \mathrm{~h}$ the PMN concentration was not significantly different from that pre-TX.

and Gro and the $\beta$-chemokine MCP-1 were all higher after 24 than after $72 \mathrm{~h}$ (fig. 6a). The fluids contained $25-50$ times more MCP-1 than IL-8 or Gro, with Gro concentrations being higher than those of IL-8. There was a significant decrease in the median Gro concentration from $400 \mathrm{pg} \cdot \mathrm{mL}^{-1}$ at $24 \mathrm{~h}$ to $<200 \mathrm{pg} \cdot \mathrm{mL}^{-1}$ after $72 \mathrm{~h}(\mathrm{p}=0.004$, Mann-Whitney). The mean IL-8 concentration also fell significantly from $175 \pm 17 \mathrm{pg} \cdot \mathrm{mL}^{-1}$ after $24 \mathrm{~h}$ to $121 \pm 47$ $\mathrm{pg} \cdot \mathrm{mL}^{-1}$ after $72 \mathrm{~h}(\mathrm{p}=0.025)$. Furthermore, the median concentration of the macrophage chemoattractant MCP-1 significantly decreased from $9,400 \mathrm{pg} \cdot \mathrm{mL}^{-1}$ to 3,050 $\mathrm{pg} \cdot \mathrm{mL}^{-1}$ over the same time period ( $\mathrm{p}=0.004$, MannWhitney). In the group in which talc was used as the sclerosant, the concentration of each chemokine was higher than that in the group in which TCN was used. Unlike in the TCN-treated rabbits, there was no change in Gro concentration, and the median IL-8 concentration increased significantly from $600 \mathrm{pg} \cdot \mathrm{mL}^{-1}$ at $24 \mathrm{~h}$ to $6,330 \mathrm{pg} \cdot \mathrm{mL}^{-1}$ at $72 \mathrm{~h}(\mathrm{p}=0.028)$. The MCP-1 concentrations in talctreated rabbits, however, paralleled those seen in the TCN group, and significantly decreased from a mean of 30,400 $\mathrm{pg} \cdot \mathrm{mL}^{-1}$ to $4,400 \mathrm{pg} \cdot \mathrm{mL}^{-1}$ between 24 and $72 \mathrm{~h}$ post-sclerosant administration $(\mathrm{p}=0.0002)$. 


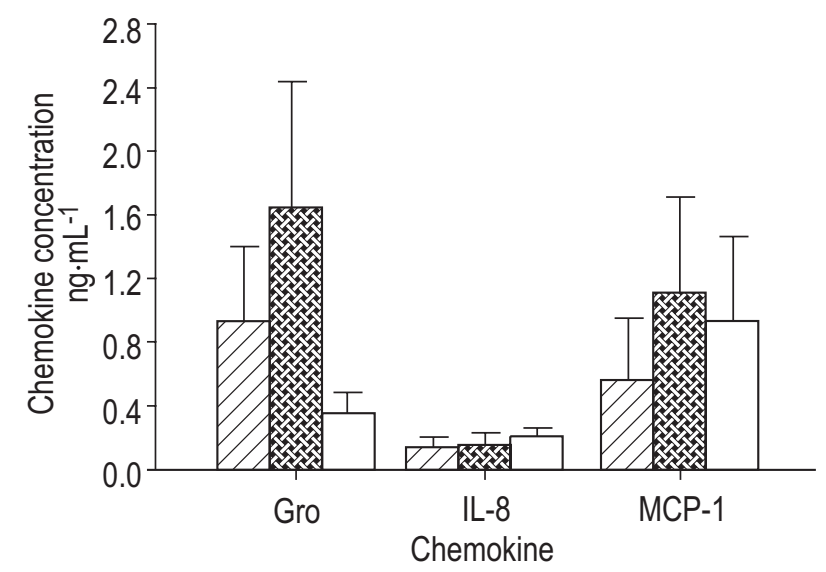

Fig. 3. - Peripheral blood chemokine concentrations following tetracycline $(\mathrm{TCN})$ administration. Chemokine concentrations in the blood were measured prior to $(\mathbb{Z})$, and 24 (ख) and $72 \mathrm{~h}$ after $(\square)$, TCN administration using specific enzyme-linked immunosorbent assays. There were no significant changes in any of the blood chemokine concentrations following TCN administration $(\mathrm{p}>0.05)$. Data are presented as meansd. Pre-TX: pretreatment; Gro: growth-related protein; IL-8: interleukin-8; MCP-1: monocyte chemotactic protein-1.

Histopathological analysis confirmed that the neutrophilic pleocytosis noted at day 1 in pleural fluids was accompanied by acute inflammation associated with infiltration of the pleural and subpleural areas by neutrophils (fig. 7a). By day 3, more macrophages were noted in the pleural infiltrate (fig. 7b). At day 3, fibrinous transpleural adhesions had formed and were noted to contain detectable collagen fibrils (fig. 7c). The mesothelial surface of the intact rabbit parietal pleura stained positively (red) for IL-8 (fig. 7d). At day 1, the mesothelial surface retained IL-8 reactivity (fig. 7e), whereas little staining was detectable by day 3 (fig. 7f). These data demonstrate that the mesothelial lining of the pleural compartment constitutively expresses IL-8. IL-8 expression by the mesothelium is retained early after TCN-induced pleuritis but falls when pleural remodelling and fibrosis are apparent.

Immunohistochemistry showed that the IL-8 was derived, at least in part, from production by the pleural mesothelial cell layer (fig. 7). The staining was consistent with the pleural fluid IL-8 content, and was evident after $24 \mathrm{~h}$, but no IL-8 expression was detected after $72 \mathrm{~h}$. Neither Gro nor MCP-1 could be demonstrated in rabbit pleural tissue using polyclonal antibodies directed against the rabbit antigens.

\section{Discussion}

TCN and its derivatives have proven to be effective sclerosing agents in the treatment of pleural effusions $[2$, 3 ], particularly those that occur in patients with malignancy [1]. These compounds are relatively inexpensive, and when used to accomplish pleurodesis are associated with low morbidity rates [12]. Systemic and topical administration of TCN has been shown to suppress neutrophil chemotaxis [13]. Conversely, when injected directly into the pleural space, TCN causes an initial neutrophil influx into the pleural space, which is followed by an increase in

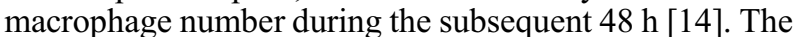

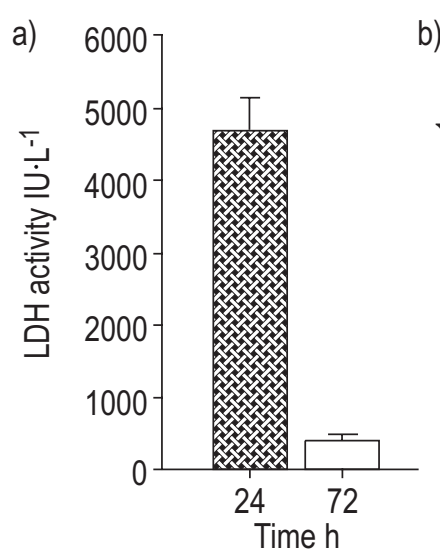

b)

Fig. 4. - Lactate dehydrogenase activity (a) (LDH) and total protein concentration (b) in pleural fluid following tetracycline administration. After $72 \mathrm{~h}$, the median LDH activity of the pleural fluid decreased significantly from that at $24 \mathrm{~h}(\mathrm{p}=0.002$, Mann-Whitney). However, there was no significant change in the total protein concentration over the same period $(\mathrm{p}=0.41)$. Data are presented as mean \pm SD.

inflammatory cell response is probably an important component in the progression to subsequent pleural fibrosis. While chemokines and IL-8 are implicated in the inflammatory response, their expression and temporal distribution in TCN-induced pleuritis has not, to the authors' knowledge, been previously characterized.

In the present study, the elaboration of chemokines within the first $72 \mathrm{~h}$ following sclerosant administration was investigated. The 24 and $72 \mathrm{~h}$ intervals were chosen for study in order to evaluate the expression of selected chemokines during an initial acute inflammatory phase (24 h) during which pleural loculation and fibrosis had not yet occurred and a later phase $(72 \mathrm{~h})$ characterized by florid loculation, pleural fibrosis and collagen deposition within transpleural adhesions. Previously, it had been found that IL-8, a neutrophil chemotactic member of the $\alpha$-chemokine family, is expressed in the pleural space of patients

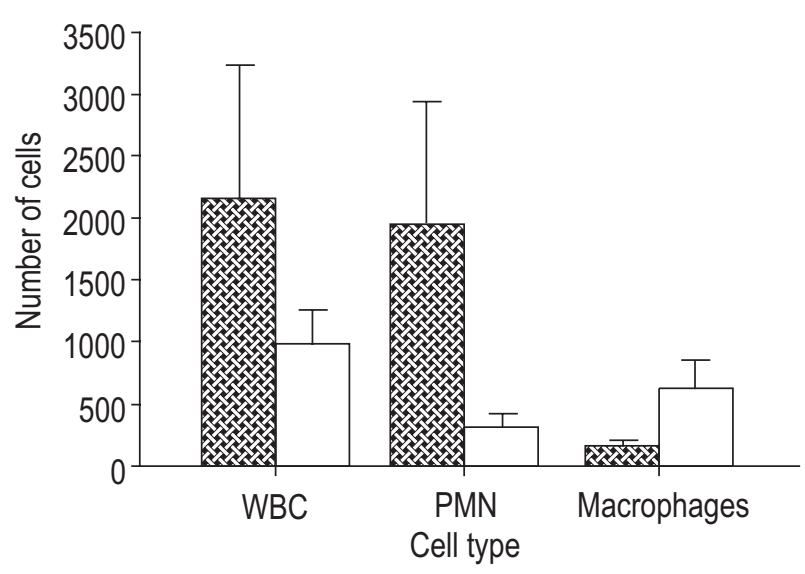

Fig. 5. - Changes in cellular content of pleural fluid 24 (烝) and $72 \mathrm{~h}$ ( $\square$ ) following tetracycline (TCN) administration. The Mann-Whitney rank-sum test indicated that the median concentration of polymorphonuclear neutrophil (PMNs) in the pleural fluid $24 \mathrm{~h}$ after TCN administration was significantly higher $(p=0009)$ than that after $72 \mathrm{~h}$. However, there was no significant difference in the median concentration of total white blood cells (WBCs) in the pleural fluid after 24 or $72 \mathrm{~h}(\mathrm{p}=0.485)$. Nor was there a significant difference between the mean pleural macrophage concentration at 24 and $72 \mathrm{~h}$ after TCN administration. Data are presented as mean \pm SEM. 

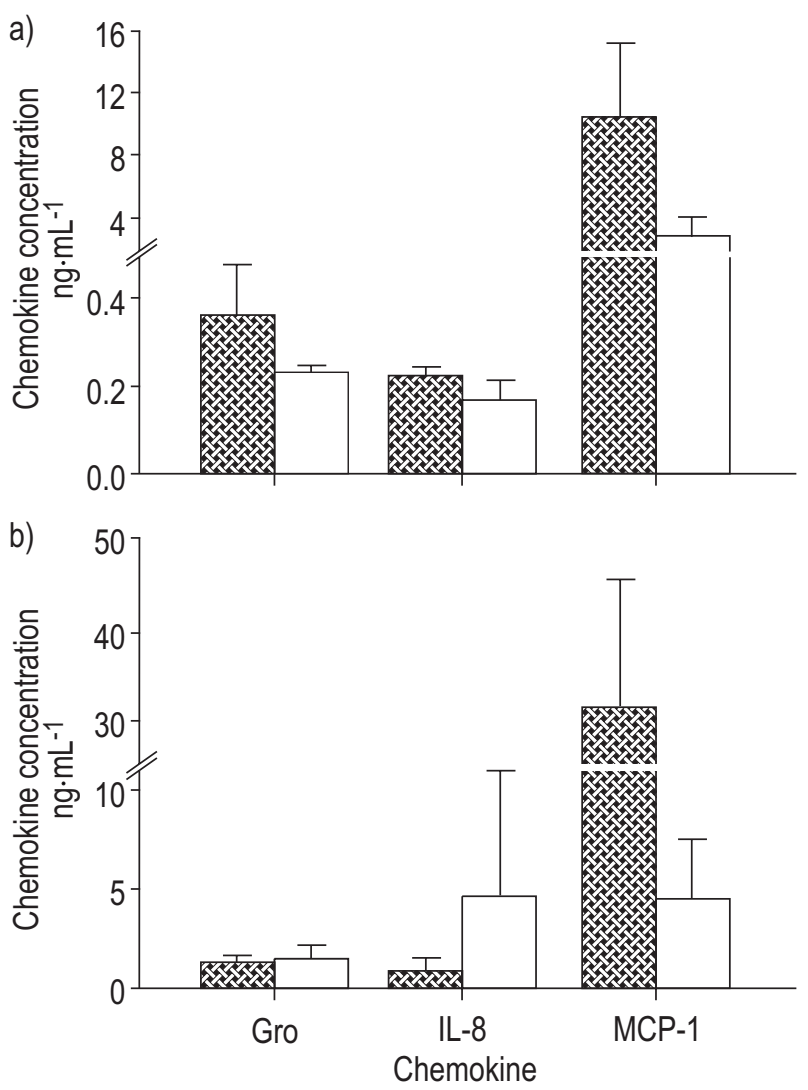

Fig. 6. - Changes in pleural fluid chemokine content following sclerosant administration. Chemokine concentrations in the pleural fluid were measured 24 ( ) and $72 \mathrm{~h}(\square)$ after: a) tetracycline; and b) talc administration, using specific enzyme-linked immunosorbent assay. Following TCN administration, there was a significant decrease in the median growth-related protein (Gro) concentration after $72 \mathrm{~h}$ ( $\mathrm{p}=0.004$, MannWhitney). The mean interleukin-8 (IL-8) concentration also fell significantly between 24 and $72 \mathrm{~h}(\mathrm{p}=0.025)$. Furthermore, the median concentration of the macrophage chemoattractant monocyte chemotactic protein-1 (MCP-1) significantly decreased over the same time period $(p=0.004$, Mann-Whitney) and a decrease in the mean MCP-1 concentration ( $\mathrm{p}=0.0002$, Mann-Whitney). There were no significant changes, between 24 and $72 \mathrm{~h}$, in Gro concentration $(\mathrm{p}=0.84)$.

with exudative pleural effusions [15]. Since TCN itself induces an exudative effusion [16], this study sought to determine whether IL-8 and Gro, another neutrophil activator of the $\alpha$-chemokine family, were locally expressed during the course of TCN-induced fibrosing pleuritis. Also, a group of rabbits were treated with a separate sclerosing agent, talc, so that the chemokine expression in the two models could be compared.

It was found that the pleural fluid mean IL-8 concentration fell significantly between 24 and $72 \mathrm{~h}$ following TCN administration. The production of IL-8 appears, at least in part, to derive from the mesothelial cells. No IL-8 immunoreactivity was identified in these cells after $72 \mathrm{~h}$, which was consistent with the fall in IL- 8 concentration noted in the pleural fluid. Given that IL-8 immunoreactivity was identified in the native mesothelial lining, it may be that local release into the pleural exudate that forms after injury establishes a chemotactic gradient that attracts neutrophils into the pleural space. Other chemoattractants, such as thrombin, may likewise differentially attract neutrophils to the injured pleura. While the control of intrapleural inflammatory cell traffic is probably multifactorial, the present data suggest that local elaboration of IL-8 contributes to the pleural fluid neutrophilia observed at day 1 . The decrease in pleural fluid IL-8 concentration at day 3 in the TCN-treated animals correlates with a fall in pleural fluid neutrophil numbers, further suggesting that IL-8 is involved in the local regulation of inflammatory cell traffic in this form of pleuritis. This scenario is similar to the pattern of events that occur in acute lung injury associated with adult respiratory distress syndrome (ARDS) [5]. Irrespective of the precipitating cause of ARDS, IL- 8 is found in elevated concentrations in the airspaces, and is largely responsible for the neutrophil chemotactic activity. The prolonged production of IL-8 seen in the talctreated rabbits may be due to the particulate nature of the sclerosant, resulting in a slower clearance of the irritant from the pleural space. The influx of neutrophils and subsequent alveolitis in animal models of acute lung injury can be blocked by either $\alpha$-chemokine receptor inhibitors [17] or antibodies to IL-8 [18, 19]. IL-8, therefore, appears to regulate inflammatory cell traffic during evolving injury in both pleural and alveolar components and the authors infer that its expression may likewise contribute to the progression of pleural injury during pleuritis induced by sclerosing materials.

VILLARD et al. [20] found that, in pneumonia and ARDS, the IL- 8 concentration in the airspaces correlated with the concentration of Gro, another neutrophil chemotactic member of the $\alpha$-chemokine family. The present study, therefore, sought to determine whether Gro was also expressed following TCN challenge. Local expression of Gro, as well as MCP-1, was found to be altered during the course of TCN-induced pleuritis. There was a significant decrease in the median Gro concentration from $400 \mathrm{pg} \cdot \mathrm{mL}^{-1}$ at $24 \mathrm{~h}$ to $<200 \mathrm{pg} \cdot \mathrm{mL}^{-1}$ after $72 \mathrm{~h}$. In the talc-treated animals, there was considerably more Gro in the pleural fluid, with a mean concentration of $1,300 \mathrm{pg} \cdot \mathrm{mL}^{-1}$ being detected on both days. This pattern of Gro expression is consistent with that described in a study examining the elaboration of cytokines in dermal inflammation induced by sulphur mustard [21]. In that study, TsurutA et al. [21] found that mononuclear cell expression of messenger ribonucleic acid (mRNA) encoding Gro was at a maximum 2 days following dermal injury. In situ hybridization techniques using probes that recognize all three forms of Gro $(\alpha, \beta$ and $\gamma)$ showed that Gro mRNA in mononuclear cells in the lesion was only slightly decreased by 6 days following injury. In the present study, using antibodies raised against rabbit Gro, it has been shown that the accumulation of this specific cytokine in pleural effusions decreases more rapidly, and is significantly decreased after $72 \mathrm{~h}$. Previous in vitro studies of Gro production in rabbit alveolar macrophages [22] showed that maximal accumulation occurred between 4 and $22 \mathrm{~h}$ after stimulation. This study also used in situ hybridization techniques to show the production of Gro by macrophages and neutrophils in a rabbit model of Escherichia coli pneumonia. These observations suggest that some of the Gro in the pleural fluid may, at least in part, be derived from the neutrophils that entered the pleural space. Since Gro is also a neutrophil chemotaxin, it could also stimulate pleural neutrophilia and amplify 

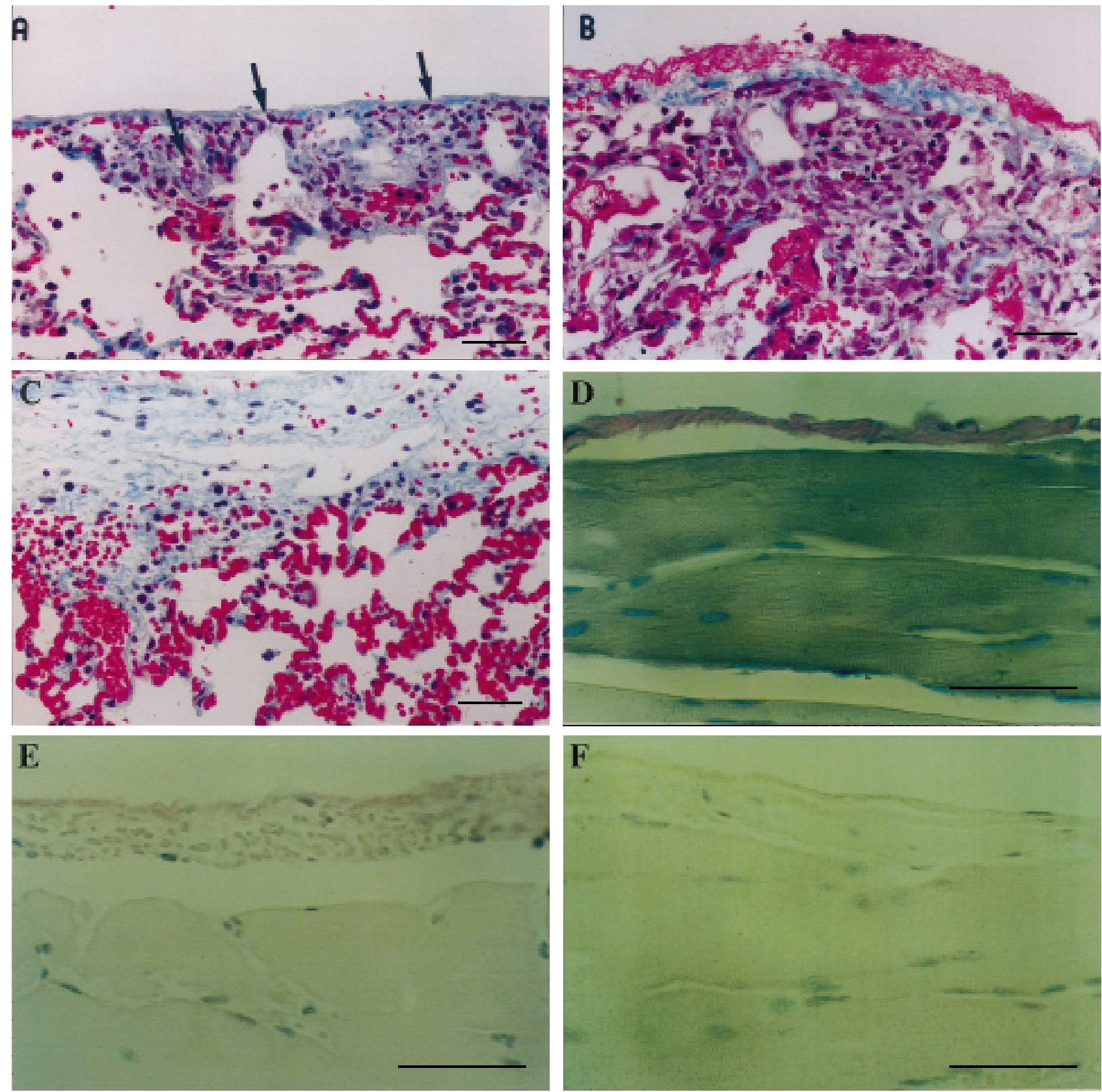

Fig. 7. - A) Pleural and subpleural acute inflammation $24 \mathrm{~h}$ after induction of tetracycline (TCN) pleuritis. Arrows indicate polymorphonuclear neutrophils within the inflammatory foci. (haematoxylin and eosin stain) B) Persistent pleural and subpleural inflammation $72 \mathrm{~h}$ after administration of intrapleural TCN. C) Formation of collagen within intrapleural adhesions $72 \mathrm{~h}$ after intrapleural TCN administration. Collagen fibrils are stained blue. (Trichrome stain). D) Immunohistochemical identification of interleukin-8 (IL-8) (red staining) in the mesothelial lining of the intact (uninjured) rabbit pleura, using polyclonal antiserum. E, F) Immunohistochemical identification of IL-8 in rabbit pleural tissue 24 and $72 \mathrm{~h}$ after intrapleural TCN administration, respectively (Internal scale bar=25 $\mu \mathrm{m}$ ).

the neutrophil influx early in the course of both TCN- and talc-induced pleuritis.

Since there were changes in the macrophage population, the pleural fluid was also examined for the $\beta$-chemokine macrophage chemoattractant MCP-1. The median concentration of MCP-1 significantly decreased from 9,400 $\mathrm{pg} \cdot \mathrm{mL}^{-1}$ at $24 \mathrm{~h}$ to $3,050 \mathrm{pg} \cdot \mathrm{mL}^{-1}$ after $72 \mathrm{~h}$, inversely correlating with the increase in pleural macrophages at this same time interval. Similar changes were noted in the talc-treated animals. Although the concentrations of this chemokine were again higher than in the TCN-treated animals, there was a significant decrease from the 24 to the $72 \mathrm{~h}$ value. These observations suggest that other factors may be responsible for the increase in the number of macrophages in the pleural space. In a recent study, BirdSALl et al. [23] examined the attraction of monocytes into the canine myocardium following reperfusion and determined that monocyte migration was induced by a series of factors. The initial attraction resulted from complement component C5a, transforming growth factor- $\beta 1$ (TGF- $\beta 1$ ) and MCP-1 acting sequentially. However, after $3 \mathrm{~h}$, the chemotactic activity was mainly due to MCP-1 and TGF- $\beta 1$ 
acting together. Therefore, it is probable that $24 \mathrm{~h}$ after TCN administration, the monocytes in the pleural space have been recruited by a series of attractants including MCP-1.

In conclusion the expression of at least two neutrophil and one macrophage chemoattractants following the instillation of either tetracycline or talc into the pleural space have been confirmed. This is associated with leukocyte influx into the area. The initial influx of neutrophils is, at least in part, attributable to interleukin- 8 and is replaced by an increased macrophage presence after $72 \mathrm{~h}$. However, the role of monocyte chemotactic protein-1 is less certain, and locally elaborated chemoattractants, may affect the pleural fluid macrophage predominance observed later on in the course of tetracycline- and talc-induced injury.

\section{References}

1. Light RW. Malignant pleural effusions. In: Anonymous (ed.), Pleural Diseases, Malvern, PA: Lea \& Febiger, 1990, pp. 97-115.

2. Gravelyn TR, Michelson MK, Gross BH, Sitrin RG. Tetracycline pleurodesis for malignant pleural effusions: a 10year retrospective study. Cancer 1987; 59: 1973-1977.

3. Sherman S, Grady KJ, Seidmen JC. Clinical experience with tetracycline pleurodesis of malignant pleural effusions. South Med J 1987; 80: 716-719.

4. Rubinson RM, Bolooki H. Intrapleural tetracycline for control of malignant pleural effusion: a preliminary report. Youth Med J 1972; 65: 847-849.

5. Miller EJ, Cohen AB, Nagao S, et al. Elevated levels of NAP-1/Interleukin-8 are present in the airspaces of patients with the adult respiratory distress syndrome and are associated with increased mortality. Am Rev Respir Dis 1992; 146: 427-432.

6. Xie C, McGovern JP, Wu W, Wang NS, Light RW. Comparisons of pleurodests induced by talc with or without thymol iodide in rabbits. Chest 1998; 113: 795-799.

7. Strange C, Allen ML, Harley R, Lazarchick J, Sahan SA. Intrapleural streptokinase in experimental empyema. Amer Rev Respir Dis 1993; 147: 962-966.

8. Fox-Dewhurst R, Alberts MK, Kajikawa O, et al. Pulmonary and systemic inflammatory responses in rabbits with gram-negative pneumonia. Amer Resp \& Crit Care Med 1997; 155: 2030-2040.

9. Kajikawa O, Goodman RB, Johnson MC, Konishi K, Martin TR. Sensitive and specific immunoassays to detect rabbit IL-8 and MCP-1: cytokines that mediate leukocyte recruitment to the lungs. JImmunol Meth 1996; 197: 19-29.

10. Idell S, Pueblitz S, Emri S, et al. Regulation of fibrin deposition by malignant mesothelioma. Am J Pathol 1995; 147: 1318-1329.

11. Sylvester I, Rankin JA, Yoshimura T, Tanaka S, Leonard EJ. Secretion of neutroplil attractant/activation protein by lipopolysaccharide-stimulated lung macrophages determined by both enzyme-linked immunosorbent assay and N-terminal sequence analysis. Am Rev Resp Dis 1990; 141: 683-688.

12. Bayly TC, Kisner DL, Sybert A, Macdonald JS, Tsou E, Schein PS. Tetracycline and quinacrine in the control of malignant pleural effusions. A randomized trial. Cancer 1997; 41: 1188-1192.

13. Elewski BE, Lamb BA, Sams WMJ, Gammon WR. In vivo suppression of neutrophil chemotaxis by systemically and topically administered tetracycline. J Amer Acad Dermatol 1983; 8: 807-812.

14. Strange C, Tomlinson JR, Wilson C, Harley R, Miller KS, Sahn SA. The histology of experimental pleural injury with tetracycline, empyema, and carageenan. Exp Mol Pathol 1989; 51: 205-219.

15. Miller EJ, Idell S. Interleukin-8 (IL-8): An important neutrophil chemotaxin in some cases of exudative pleural effusions. Exp Lung Res 1993; 19: 589-601.

16. Salm SA, Potts DE. The effects of tetracycline on rabbit pleura. Am Rev Respir Dis 1978; 117: 493-499.

17. Miller EJ, Cohen AB, Peterson BT. Peptide inhibitor of interleukin-8 (IL-8) reduces staphylococcal-enterotoxin A (SEA) induced neutrophil trafficking to the lung. Inflamm Res 1996; 45: 393-397.

18. Folkesson HG, Matthay MA, Hebert CA, Broaddus VC. Acid aspiration-induced lung injury in rabbits is mediated by interleukin-8-dependent mechanisms. J Clin Invest 1995; 96: 107-116.

19. Yokoi K, Mukaida N, Harada A, Watanabe Y, Matsushima $\mathrm{K}$. Prevention of endotoxemia-induced acute respiratory distress syndrome-like lung injury in rabbits by a monoclonal antibody to il-8. Lab Invest 1997; 76: 375-384.

20. Villard J, Dayer-Pastore F, Hamacher J, Aubert JB, Schlegel-Haueter S, Nicod LP. GRO alpha and interleukin-8 in Pneumocystis carinii or bacterial pneumonia and adult respiratory distress syndrome. Am J Resp Crit Care Med 1995; 152: 1549-1554.

21. Tsuruta J, Sugisaki K, Dannenberg AM, Yoshimura T, Abe Y, Mounts P. The cytokines NAP-1 (IL-8), MCP-1, IL-1 beta, and Gro in rabbit inflammatory skin lesions produced by the chemical irritant sulfur mustard. Inflammation 1997; 20: 293-318.

22. Johnson II MC-, Kajikawa O, Goodman RB, et al. Molecular expression of the $\alpha$-chemokine rabbit GRO in Eschericia coli. and characterization of its production by lung cells in vitro and in vivo. J Biol Chem 1996; 271 : 10853-10858.

23. Birdsall HH, Green DM, Trial J, et al. Complement C5a, TGF-beta 1, and MCP-1, in sequence, induce migration of monocytes into ischemic canine myocardium within the first one to five hours after reperfusion. Circulation 1997; 95: 684-692. 